\title{
Desenvolvimento de tomate de mesa, com o uso do método QFD (Desdo- bramento da Função Qualidade), comercializado em um supermercado ${ }^{1}$
}

\author{
Sissi K. Marcos²; José Tadeu Jorge ${ }^{3}$ \\ ${ }^{2}$ Fundação Educacional de Barretos, Av. Prof. Roberto Frade Monte, 389, 14.783-226, Barretos-SP. E-mail: sissi@feb.br ${ }^{3}$ UNICAMP, \\ FEAGRI, Cidade Universitária Zeferino Vaz, C. Postal 6011, 13.081-970, Campinas-SP. E-mail: tadeu@agr.unicamp.br
}

\section{RESUMO}

Para atender as exigências do consumidor, relativas ao tomate de mesa, oferecendo um produto de qualidade, e reduzir as perdas pós-colheita, aplicou-se o método QFD ao tomate comercializado em um supermercado. Avaliou-se o potencial de uso dessa ferramenta, bem como sua aplicabilidade a um produto hortícola, tendose realizado o desdobramento da qualidade, com o trabalho conduzido na loja Carrefour D.Pedro, em Campinas. Desenvolveu-se um produto a partir das características exigidas pelo consumidor, estabelecendo-se como concorrente o tomate 'Carmem'. A cada etapa do método, as decisões foram tomadas após discussões norteadas pelas características inerentes ao produto e suas relações com a metodologia. O lote piloto, com as características exigidas pelos clientes e condizentes com as estratégias da empresa (supermercado), foi avaliado junto aos consumidores e atingiu as metas estabelecidas para a qualidade planejada, bem como o objetivo relativo a perdas, tendo-se alcançado o valor de $0 \%$ de perdas. No teste de preferência, em que se comparou o produto desenvolvido com o tomate 'Carmem', através de análise sensorial, o tomate desenvolvido através do método QFD foi o preferido ao nível de $0,1 \%$ de significância. Os resultados obtidos comprovaram a aplicabilidade do método QFD a produtos agrícolas comercializados in natura, tendo-se alcançado os benefícios esperados.

Palavras-chave: Lycopersicon esculentum, planejamento da qualidade, pós-colheita, comercialização, varejo, consumidor.

\begin{abstract}
Development of fresh tomato, using the QFD (Quality Function Deployment) method, commercialized in a supermarket

To attend the consumer's requirements related to the fresh tomato, offering a product of quality and to reduce the post-harvest losses of the product, the QFD method was applied to the tomato commercialized in a supermarket. The potential use of this tool was appraised, as well as its applicability to an agricultural product, taking effect the QFD. The experiment was carried out at the Carrefour store in Campinas, Brazil. A product with the requirements demanded by the consumer was developed, having the 'Carmen' tomato (popularly known by long shelf life) as the rival, which retains the biggest share in market nowadays. At each step of the experiment, the decisions were taken, considering the inherent characteristics to the product and its relations with the methodology. The pilot lot, with characteristics demanded by the clients and suitable to the business strategy (supermarket), was evaluated with the consumers. The established goal in relation to quality was reached, as well as the aim related to losses. Losses were $\%$. As to the preference test, in which the developed product and 'Carmen' tomato were compared, through sensorial analysis, the tomato developed by the QFD method was the favorite with $0,1 \%$ significance level. The results obtained proved the applicability of the QFD method to fresh agricultural products commercialized, and the expected benefits were reached.
\end{abstract}

Keywords: Licopersicon esculentum, quality planning, postharvest, commercialization, retail trade, consumer.

\section{(Recebido para publicação em 08 de novembro de 2001 e aceito em 25 de março de 2002)}

$\mathrm{O}$ tomate é uma das hortaliças de maior importância econômica no mundo (FAO, 1998), estando o Brasil em oitavo lugar na produção mundial e em sétimo no processamento (Camargo Filho, 2001). Segundo Della Vecchia \& Koch (2000), o tomate 'Carmem', denominado "longa vida", representa cerca de $70 \%$ do mercado atual, devido à maior flexibilidade que oferece ao produtor na hora da colheita, e menor perda nas operações de preparo, transporte e comercialização. Porém, Castro (2000), ao avaliar o sabor, verificou que a cultivar "Santa Clara" alcançou valo- res mais elevados que a cv. Carmem em testes sensoriais. Observam-se elevados valores de perdas em tomates, e, conforme Costa \& Caixeta Filho (1996), estas ocorrem principalmente em nível de varejo. Para Okezie (1998), a tecnologia pós-colheita tem papel crucial para a segurança alimentar mundial, frente à projeção da FAO de uma população mundial de 8,3 bilhões de pessoas em 2025 , e afirma que pouco esforço é dispensado à redução de perdas de produtos após sua colheita.

Segundo Costa \& Caixeta Filho (1996), no estado de São Paulo, a estru- tura de comercialização mais comum para o tomate de mesa é a que passa por quatro agentes (produtor, intermediário, atacadista e varejista) antes de chegar ao consumidor. Já Fonseca et al. (1998) afirmam que no Brasil os varejistas modernos que comercializam hortifrutícolas são os supermercados e hipermercados. Belik \& Chaim (1999) relatam que, a princípio, os supermercados viam a venda de hortifrutícolas como um importante elemento estratégico para atração do consumidor ao ponto de venda, e afirmam que o crescimento do consumo de alimentos frescos e a

1 Parte da tese de doutorado do primeiro autor, apresentada à FEAGRI - UNICAMP 
busca por produtos de melhor qualidade os forçaram a dedicar maior espaço de venda para a comercialização destes produtos. Dados da Associação Brasileira de Supermercados (2001) dão conta que, no Brasil, esse setor é hoje responsável por $85 \%$ do abastecimento nacional de alimentos e produtos de higiene e limpeza, sendo que o setor de perecíveis representa $33,5 \%$ de suas vendas.

Vilela \& Macedo (2000) relatam que, hoje, o poder e a liderança no agronegócio das hortaliças, no Brasil, migraram para o segmento da distribuição, onde os consumidores passaram a representar os agentes econômicos ativos no processo. Segundo os autores, é o consumidor quem realmente detém o poder, sinalizando os caminhos a serem percorridos na busca da eficácia por parte das empresas do setor de alimentos, que encontram dificuldades à medida que os mercados tornam-se saturados.

No Brasil, tem-se observado mudanças intrigantes no comportamento do consumidor, impulsionadas pela estabilidade econômica: passou a ser questionador, ciente do seu poder de barganha e nada fiel: busca qualidade e comodidade, procura produtos frescos, com bons preços, além de um ambiente seguro e disponível em seu horário livre (Hortifruti, 2000).

No tocante à qualidade, Cheng et al. (1995) afirmam que as empresas brasileiras têm dispensado grande esforço no sentido de implementar ações gerenciais de manter e melhorar a qualidade, e, para complementar este esforço e permitir uma ampliação da vantagem competitiva, é necessário inteirá-lo com a ação gerencial do planejamento da qualidade. As empresas que atuam na ponta final da cadeia de consumo, cujo cliente é o consumidor final, como é o caso dos supermercados, geralmente, têm alguma estrutura de desenvolvimento de produtos, porém, é comum observarem-se certas deficiências comuns de gestão de desenvolvimento.

O método QFD propõe-se a operacionalizar o planejamento da qualidade ou a gestão de desenvolvimento do produto, podendo ser aplicada tanto a produto (bens e serviços) da empresa quanto a produto intermediário entre cliente e fornecedor interno. Esse método visa desdobrar a qualidade, utilizando a lógica da causa e efeito, de forma sistematizada. O desdobramento parte da voz do cliente, passando por características da qualidade até chegar a um determinado valor de um parâmetro de controle do Padrão Técnico do Processo, sendo que por desdobramento da qualidade entende-se: buscar, traduzir e transmitir as exigências dos clientes em características de qualidade do produto através de desdobramentos sistemáticos (Cheng et al., 1995).

O método QFD tem sido empregado com sucesso em indústrias mecânicas e de montagem, de alimentos processados e várias outros setores (Cheng et al., 1995), porém, nunca foi avaliado no planejamento da qualidade de um produto agrícola in natura. Assim, este trabalho visou avaliar a aplicabilidade desse método no planejamento da qualidade de um hortícola, o tomate de mesa, comercializado em uma loja da rede Carrefour, realizando o desdobramento da qualidade no setor de pós-colheita do produto.

\section{MATERIAL E MÉTODOS}

O ambiente de trabalho foi o supermercado D. Pedro da rede Carrefour, localizado na cidade de Campinas. A cultivar Carmem foi escolhida como concorrente do tomate a ser desenvolvido, do grupo alongado, identificado como "nosso" tomate.

A metodologia utilizada foi a QFD, segundo Cheng et al. (1995), aplicando-se suas etapas: 1) Identificação das necessidades dos clientes; 2) Estabelecimento do conceito do produto; 3) Projeto do produto e do processo; 4) Estabelecimento dos padrões-proposta; 5)Fabricação e teste do lote piloto; 6) Avaliação da satisfação do cliente; 7) Estabelecimento da padronização final; 8) Reflexão sobre o processo de desenvolvimento.

$\mathrm{Na}$ etapa 1 , realizou-se a Pesquisa Qualitativa através da realização de 32 entrevistas, ao longo de dois dias, junto a pessoas que encontravam-se na banca de tomates da loja, utilizando um questionário com as perguntas: $\mathrm{O}$ que você espera do tomate de mesa?; Na sua opinião, qual seria o produto ideal?; Quais problemas você já teve com tomate de salada, no passado? Os itens de qualidade exigida levantados foram organizados em uma Tabela de Desdobramento da Qualidade Exigida, utilizando-se diagrama de afinidades. O Questionário da Pesquisa Quantitativa baseou-se nos itens de qualidade exigida do nível secundário da Tabela obtida anteriormente (aparência externa, cor esverdeada, firmeza, sabor adocicado, forma alongada, tamanho médio, durabilidade, aparência interna, ausência de agrotóxico, adequado para salada), avaliando o grau de importância de cada um deles, bem como o desempenho do tomate 'Carmem' e o "nosso" tomate, utilizando escalas balanceadas com ponto neutro (variando de Nenhuma Importância, nota 1, até Muito Importante, nota 5, para Grau de Importância; e de Péssimo, nota 1 , a Ótimo, nota 5 , para Desempenho dos tomates). Realizou-se amostragem piloto e análise de variância dos dados obtidos, utilizando-se, a seguir, equação proposta por Cochran (1977), com $\mathrm{t}=2$ e $\mathrm{r}=10 \%$, para definição do número de questionários a serem aplicados na Pesquisa Quantitativa, que entrevistou 134 consumidores que encontravam-se na banca de tomates da loja. Os dados obtidos foram tabulados, sendo calculada a mediana para cada item avaliado. A Qualidade Planejada foi definida em reunião com representante do supermercado, com representante dos produtores, com representantes do Centro de Qualidade da CEAGESP, com professores e pósgraduandos da área de pós-colheita da FEAGRI-UNICAMP, obtendo-se o Plano de Qualidade, numa escala de 1 a 5 , para cada item de qualidade exigida $\mathrm{e}$ definindo-se o item que seria usado como Argumento de Venda (valor para Argumento de Venda Especial $=1,5 \mathrm{e}$ Comum $=1,2$ ). A partir do plano de qualidade, calculou-se o Índice de Melhoria (=Plano de Qualidade /Avaliação do "nosso" tomate) e o Peso Absoluto (=Grau de Importância x Índice de Melhoria x Argumento de Venda) e Relativo (= valor percentual) de cada item avaliado.

A etapa 2 foi realizada em reunião com o Diretor do Carrefour responsá- 
vel pelos produtos com Garantia de Origem, chegando-se ao Conceito do Produto.

Na etapa 3, traduziu-se a voz do cliente em Qualidade Projetada, elaborando-se a Matriz da Qualidade. Realizouse reunião de pessoas relacionadas à área de pós-colheita, extraindo-se características técnicas do produto a partir dos itens de qualidade exigida. Obteve-se a correlação entre os itens de qualidade exigida e as características de qualidade do produto, anotando-se, na Matriz, a intensidade da correlação, quando existente. Efetuou-se a conversão da importância dada às características exigidas para as características da qualidade, multiplicando-se o Peso Relativo da característica exigida pelo valor da correlação (Forte=9; Média=3; Fra$\mathrm{ca}=1$ ) correspondente. Para realizar a comparação com a concorrência, elaborou-se uma Tabela em que estabeleceuse critérios para conceituar os itens de característica de qualidade do tomate 'Carmem' e do "nosso" tomate. Fizeram-se análises da Matriz da Qualidade, que possibilitaram estabelecer a Qualidade Projetada.

Para realizar a etapa 4, seguiu-se a lógica de sistemas, com o seguinte raciocínio: Quais os atributos que o tomate deve ter para atender à Qualidade Projetada?; Para possuir esses atributos, quais operações devem ser realizadas?; Estas operações necessitam de quais materiais auxiliares?; Como devem ser os procedimentos para a execução destes processos? Esse raciocínio permitiu chegar ao Modelo Conceitual para o produto em desenvolvimento. A seguir, estabeleceram-se os procedimentos, discutindo-se cada um dos processos obtidos e sua interação com os insumos necessários levantados. Em reunião com representante do supermercado, produtor, fornecedor de sementes e pessoas da área de pós-colheita, chegou-se ao Padrão Proposta para o produto. Discutindo-se os resultados parciais obtidos, chegou-se à Tabela de Garantia da Qualidade e ao Padrão Técnico do Processo.

A denominação da etapa 5, Fabricar e Testar o Lote piloto, foi alterada para Preparar e Testar o Lote piloto. Seguiram-se os procedimentos elaborados na etapa anterior, obtendo-se Lote piloto composto de 32 caixas, de $10 \mathrm{~kg}$ cada, do produto com as características de qualidade definidas anteriormente. Retirou-se uma amostra do talhão, 7 dias antes da colheita, e enviou-se para o Laboratório de Resíduos do Instituto Biológico. O lote piloto foi testado junto a consumidores da loja.

A etapa 6 confundiu-se com parte da etapa 5, pois realizou-se teste de mercado, através de 131 entrevistas utilizando questionários em que avaliava-se o desempenho dos tomates do lote piloto e de tomates 'Carmem' nos itens de qualidade, numa escala indo de Péssimo (nota 1) a Ótimo (nota 5). Obtiveramse as medianas e suas variâncias para cada item avaliado, e compararam-se os valores obtidos com o Plano de Qualidade. Realizaram-se 80 testes de preferência, através de teste sensorial, obtendo-se o resultado com base em tabela indicada por Moraes (1988). Anotaramse dados de venda e de perdas do lote piloto.

Na etapa 7, confrontaram-se os resultados obtidos com os procedimentos e padrões utilizados, em reunião de pessoas ligadas à área de pós-colheita, com fornecedores de sementes e representantes do supermercado.

Na etapa 8 , procedeu-se à análise do desenvolvimento como um todo, baseando-se nos resultados obtidos em cada etapa e ao final do processo.

\section{RESULTADOS E DISCUSSÃO}

Etapa 1: Identificação das necessidades dos clientes

Nessa etapa, chegou-se à Figura 1, em que pode-se observar os itens de qualidade exigidos, o grau de importância de cada um deles, o desempenho do tomate 'Carmem' e do "nosso" tomate e a Qualidade Planejada.

Dos itens avaliados, a Aparência Externa do fruto e Sem Resíduo de Agrotóxicos foram considerados muito importantes, o que indica que o cliente julga o produto tomate pela impressão que tem do mesmo, concordando com apontamento de Schultz et al., citados por Lee et al. (1997), e que está realmente preocupado com a questão da saúde e de segurança, (Machado Filho et al., 1996). O Grau de Importância obtido para cada item avaliado indica o que o consumidor espera do produto.

Na definição do Plano de Qualidade, discutiu-se quais itens poderiam ser melhorados, com base na tecnologia disponível e nos resultados publicados de pesquisas em pós-colheita de tomates. Definiu-se que, empregando-se procedimentos adequados (prazo entre colheita e refrigeração máximo de 48 horas, colheita durante a manhã, cuidados no manuseio dos frutos, limpeza sem impacto), a durabilidade poderia ser aumentada no "nosso" tomate, sendo um argumento de venda comum, por diferenciar o produto dos tomates oblongos normalmente encontrados no mercado. Considerando os dados de Gorenstein (2000), discutiu-se a possibilidade de realizar adequadamente as práticas fitossanitárias na produção do tomate e, através de análise em laboratório idôneo, comprovar a inexistência de resíduos, utilizando este item como argumento de venda especial.

Essas definições balizaram-se nos valores dos Pesos Relativos desses itens em comparação com os demais, e definiu-se, ainda, que o estabelecimento de procedimentos adequados para a obtenção de boa Aparência externa era primordial.

Etapa 2: Estabelecimento do conceito do produto

Foi estabelecido o seguinte Conceito do Produto: "Oferecer produto do tipo alongado, a granel, sem resíduos de agrotóxicos, com excelente aparência externa, fresco e com sabor de tomate".

Etapa 3: Projeto do produto e do processo

Transmitiu-se a voz do cliente para características técnicas de qualidade, que podem ser mensuradas de alguma forma. Chegou-se, nesta etapa, à Figura 2, Matriz da Qualidade, na qual a Qualidade Projetada foi estabelecida com base nas seguintes características da qualidade, com suas especificações: \% defeitos leves (menos de 1\% de frutos com defeitos leves); \% defeitos graves (ausência de defeitos graves); \% frutos com sujidades (ausência de sujidades no lote); padrão de cor (lotes com padrão de cor "salada" e "colorido"); grau de firmeza (ausência de frutos "moles"); sabor "de tomate" (sabor de tomate "de 


\begin{tabular}{|c|c|c|c|c|c|c|c|c|c|}
\hline & & \multirow[b]{2}{*}{ 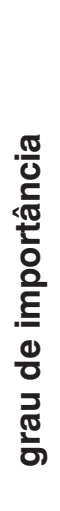 } & \multicolumn{2}{|c|}{$\begin{array}{l}\text { Avaliação } \\
\text { competitiva }\end{array}$} & \multicolumn{5}{|c|}{ Qualidade Planejada } \\
\hline & & & 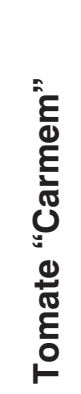 & 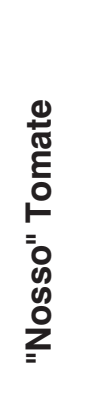 & $\begin{array}{l}\frac{0}{0} \\
\frac{\pi}{0} \\
\frac{0}{0} \\
\frac{0}{0} \\
0 \\
0 \\
\frac{0}{0} \\
\frac{0}{\frac{1}{0}} \\
\frac{\pi}{0}\end{array}$ & 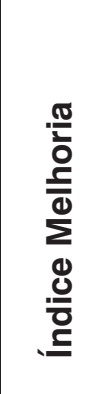 & 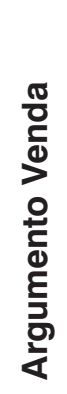 & 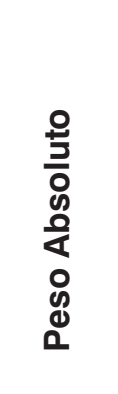 & 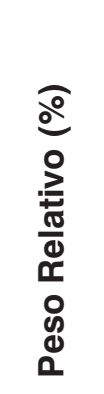 \\
\hline \multirow[t]{5}{*}{ Atributos Físicos } & Aparência Externa & 5 & 4 & 4 & 5 & 1,25 & $\mathrm{~N}$ & 6,5 & 12,3 \\
\hline & Cor esverdeada & 3 & 4 & 4 & 4 & 1 & $\mathrm{~N}$ & 3 & 5,7 \\
\hline & Firmeza & 4 & 4 & 4 & 5 & 1,25 & $\mathrm{~N}$ & 5,2 & 9,9 \\
\hline & Forma Alongada & 3 & 4 & 4 & 4 & 1 & $\mathrm{~N}$ & 3 & 5,7 \\
\hline & Tamanho Médio & 4 & 4 & 4 & 4 & 1 & $\mathrm{~N}$ & 4 & 7,6 \\
\hline \multirow[t]{2}{*}{ Atributos sensoriais } & Sabor adocicado & 4 & 4 & 4 & 4 & 1 & $\mathrm{~N}$ & 4 & 7,6 \\
\hline & Adequado $\mathrm{p} /$ salada & 4 & 4 & 4 & 4 & 1 & $\mathrm{~N}$ & 4 & 7,6 \\
\hline Conservação & Durabilidade longa & 4 & 4 & 4 & 5 & 1,25 & $\mathrm{~S}$ & 6,24 & 11,8 \\
\hline Caract. Internas & Aparência Interna & 4 & 4 & 4 & 4 & 1 & $\mathrm{~N}$ & 4 & 7,6 \\
\hline Sanidade & Ausência agrotóxic. & 5 & 3 & 3 & 5 & 1,67 & $S^{*}$ & 12,75 & 24,2 \\
\hline & & & & & & \multicolumn{2}{|l|}{ Total } & 52,69 & $100 \%$ \\
\hline
\end{tabular}

Figura 1. Estabelecimento da qualidade planejada ( $\mathrm{N}=$ não é argumento de venda, corresponde ao valor $1 ; \mathrm{S}=$ argumento de venda comum, valor 1,$2 ; \mathrm{S}^{*}=$ argumento de venda especial, valor 1,5) para tomate comercializado na loja Carrefour D. Pedro.

antigamente"); calibre (lotes com padrão de tamanho médio); "shelf-life" (duração de mais de 1 semana no domicílio do consumidor); \% frutos brocados (ausência de brocados); teor de resíduos de agrotóxicos (ausência de resíduos conprovada por análise). Essas especificações para o estabelecimento da Qualidade Projetada foram necessárias, pois, devido à grande variação entre os lotes ofertados no mercado, torna-se difícil obter os valores objetivos, ou seja, quantitativos, das características da qualidade.

Etapa 4: Estabelecimento dos padrões-proposta

Obtiveram-se a Tabela de Garantia da Qualidade (Figura 3) e o Padrão Téc- nico do Processo que definem valores limite para as características da qualidade e indicam métodos de controle dos processos. Na definição do Padrão Proposta para o produto, definiu-se pela cultivar 'Andrea', da Sakata-Agroflora, estabelecendo-se que o fornecedor do tomate em desenvolvimento deveria ser um pequeno produtor, dotado de uma estrutura física mínima e com mão-deobra familiar, pois as operações seriam manuais, uma vez que se desejava minimizar os choques mecânicos no produto e o custo da máquina para classificação de tomate oblongo ser muito elevado.

Para estabelecer a Qualidade Projetada, considerou-se que, melhorando as características \% Defeitos leves, \% Frutos com sujidades, Padrão de cor, Grau de firmeza, \% Frutos brocados, estaria promovendo-se a melhoria de Shelf life (vida de prateleira), característica de maior peso na Matriz da Qualidade. A meta definida para Sabor de Tomate exigiu a escolha de cultivar adequada, de baixa acidez.

Etapa 5: Preparo e teste do lote piloto

Nesta etapa, discutiu-se o emprego de cadeia de frio, porém, na loja o produto não é refrigerado, e, como o retardamento do resfriamento do tomate em até 4 dias após a colheita não compromete sua qualidade (Casto, 2000; Durigan \& Churata-Masca 1991), op- 


\begin{tabular}{|c|c|c|c|c|c|c|c|c|c|c|c|c|c|c|c|c|c|c|}
\hline & 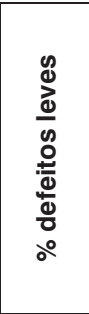 & 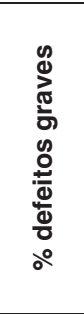 & 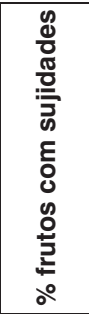 & 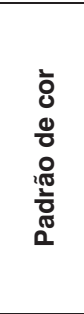 & 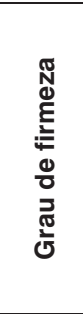 & 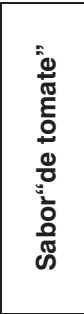 & 浐 & 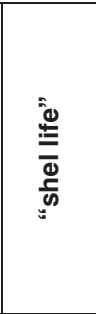 & 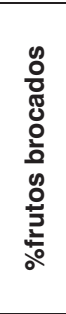 & 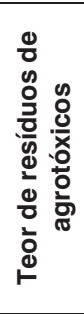 & 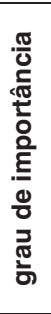 & 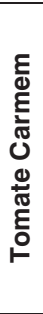 & 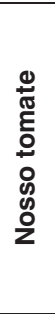 & $\begin{array}{l}\frac{0}{0} \\
\frac{\pi}{0} \\
\frac{0}{\sigma} \\
\frac{5}{0} \\
0 \\
\frac{0}{0} \\
\circ \\
\frac{0}{5} \\
\frac{\pi}{0}\end{array}$ & 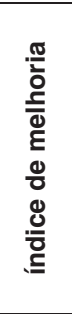 & 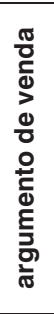 & 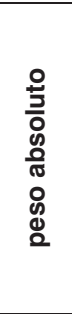 & 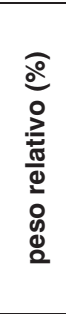 \\
\hline $\begin{array}{l}\text { Aparência } \\
\text { externa }\end{array}$ & $\begin{array}{l}\odot \\
109,8\end{array}$ & $\begin{array}{l}\odot \\
109,8\end{array}$ & $\begin{array}{l}\odot \\
109,8\end{array}$ & $\begin{array}{l}? \\
36,6\end{array}$ & $\begin{array}{l}? \\
36,6\end{array}$ & & $\begin{array}{l}? \\
36,6\end{array}$ & $\begin{array}{l}\odot \\
109,8\end{array}$ & $\begin{array}{l}? \\
36,6\end{array}$ & $\begin{array}{l}? \\
36,6\end{array}$ & 5 & 4 & 4 & 5 & 1,25 & $\mathrm{~N}$ & 6,3 & 12,2 \\
\hline $\begin{array}{l}\text { Cor } \\
\text { esverdeada }\end{array}$ & & & & $\begin{array}{l}\odot \\
52,2\end{array}$ & $\begin{array}{l} \\
52,2\end{array}$ & $\begin{array}{l} \\
52,2\end{array}$ & & $\begin{array}{l}\odot \\
52,2\end{array}$ & & & 3 & 4 & 4 & 4 & 1 & $\mathrm{~N}$ & 3 & 5,8 \\
\hline Firmeza & $\begin{array}{l}? \\
29,1\end{array}$ & $\begin{array}{l}\odot \\
87,3\end{array}$ & & $\begin{array}{l}\odot \\
87,3\end{array}$ & $\begin{array}{l}\odot \\
87,3\end{array}$ & $\begin{array}{l}? \\
29,1\end{array}$ & & $\begin{array}{l}\odot \\
87,3\end{array}$ & $\begin{array}{l}? \\
29,1\end{array}$ & & 4 & 4 & 4 & 5 & 1,25 & $\mathrm{~N}$ & 5 & 9,7 \\
\hline $\begin{array}{l}\text { Forma } \\
\text { alongada }\end{array}$ & & & & & & & $\begin{array}{l}\odot \\
52,2\end{array}$ & & & & 3 & 4 & 4 & 4 & 1 & $\mathrm{~N}$ & 3 & 5,8 \\
\hline $\begin{array}{l}\text { Tamanho } \\
\text { médio }\end{array}$ & & & & & & & $\begin{array}{l}\odot \\
69,3\end{array}$ & & & & 4 & 4 & 4 & 4 & 1 & $\mathrm{~N}$ & 4 & 7,7 \\
\hline $\begin{array}{l}\text { Sabor } \\
\text { adocicado }\end{array}$ & & & & $\begin{array}{l}\odot \\
69,3\end{array}$ & \begin{tabular}{|l|}
$?$ \\
23,1
\end{tabular} & $\begin{array}{l}\odot \\
69,3\end{array}$ & & $\begin{array}{l}\odot \\
69,3\end{array}$ & & & 4 & 4 & 4 & 4 & 1 & $\mathrm{~N}$ & 4 & 7,7 \\
\hline $\begin{array}{l}\text { Adequado } \\
\text { para salada }\end{array}$ & $\begin{array}{l}\odot \\
69,3\end{array}$ & $\begin{array}{l}\odot \\
69,3\end{array}$ & $\begin{array}{l}\odot \\
69,3\end{array}$ & $\begin{array}{l}\odot \\
69,3\end{array}$ & $\begin{array}{l}\odot \\
69,3\end{array}$ & $\begin{array}{l}\odot \\
69,3\end{array}$ & $\begin{array}{l}? \\
23,1\end{array}$ & $\begin{array}{l}\odot \\
69,3\end{array}$ & $\begin{array}{l}\odot \\
69,3\end{array}$ & $\begin{array}{l}\odot \\
69,3\end{array}$ & 4 & 4 & 4 & 4 & 1 & $\mathrm{~N}$ & 4 & 7,7 \\
\hline $\begin{array}{l}\text { Durabilidade } \\
\text { longa }\end{array}$ & $\begin{array}{l}? \\
34,8\end{array}$ & $\begin{array}{l}\odot \\
104,4\end{array}$ & $\begin{array}{l} \\
11,6\end{array}$ & $\begin{array}{l}\odot \\
104,4\end{array}$ & $\begin{array}{l}\odot \\
104,4\end{array}$ & & & $\begin{array}{l}\odot \\
104,4\end{array}$ & $\begin{array}{l}\odot \\
104, \\
4\end{array}$ & $\begin{array}{l}? \\
11,6\end{array}$ & 4 & 4 & 4 & 5 & 1,25 & S & 6 & 11,6 \\
\hline $\begin{array}{l}\text { Aparência } \\
\text { interna }\end{array}$ & $\begin{array}{l}? \\
23,1\end{array}$ & $\begin{array}{l}\odot \\
69,3\end{array}$ & & $\begin{array}{l}\odot \\
69,3\end{array}$ & $\begin{array}{l}\odot \\
69,3\end{array}$ & & & $\begin{array}{l}\odot \\
69,3\end{array}$ & $\begin{array}{l}\odot \\
69,3\end{array}$ & $\begin{array}{l}? \\
23,1\end{array}$ & 4 & 4 & 4 & 4 & 1 & $\mathrm{~N}$ & 4 & 7,7 \\
\hline $\begin{array}{l}\text { Ausência de } \\
\text { agrotóxicos }\end{array}$ & & & & & & $\begin{array}{l}\odot \\
216,9\end{array}$ & & & $\begin{array}{l}? \\
72,3\end{array}$ & $\begin{array}{l}\odot \\
216,9\end{array}$ & 5 & 3 & 3 & 5 & 1,67 & $\mathrm{~S}^{*}$ & 12,5 & 24,1 \\
\hline Peso absoluto & 266,1 & 440,1 & 190,7 & 488,4 & 442,2 & 436,8 & 181,2 & 561,6 & 381 & 357,5 & & & & & & & & \\
\hline Peso relativo & 7,1 & 11,7 & 5,1 & 13,0 & 11,8 & 11,7 & 4,8 & 15,0 & 10,2 & 10,0 & & & & & & & & \\
\hline $\begin{array}{l}\text { Tom. Carmem } \\
\text { "nosso" tom. }\end{array}$ & $\begin{array}{l}2 \\
2\end{array}$ & $\begin{array}{l}2 \\
2\end{array}$ & $\begin{array}{l}3 \\
2\end{array}$ & $\begin{array}{l}2 \\
2\end{array}$ & $\begin{array}{l}2 \\
1\end{array}$ & $\begin{array}{l}2 \\
3\end{array}$ & $\begin{array}{l}2 \\
2\end{array}$ & $\begin{array}{l}3 \\
2\end{array}$ & $\begin{array}{l}2 \\
2\end{array}$ & $\begin{array}{l}2 \\
2\end{array}$ & & & & & & & & \\
\hline $\begin{array}{l}\text { Qualidade } \\
\text { Projetada }\end{array}$ & 3 & 3 & 3 & 3 & 3 & 3 & 3 & 3 & 3 & 3 & & & & & & & & \\
\hline
\end{tabular}

Figura 2. Matriz da Qualidade para tomate comercializado na loja Carrefour D.Pedro, apresentando a Qualidade Projetada para o produto, sendo $\alpha=$ forte correlação; $m=$ média correlação; $s$ = fraca correlação; $N=$ não é argumento de venda; $S=$ argumento de venda comum; $S *$ $=$ argumento de venda especial. Campínas, SP, 2000.

tou-se por mecanismos que possibilitassem sua comercialização em até 3 dias após a colheita.

O lote piloto não continha resíduos de agrotóxicos, conforme resultados de Análise, realizada no Laboratório de Resíduos, do Instituto Biológico, sendo afixado cartaz, junto à banca, divulgando este resultado, usando-o como argumento de venda. O quilo do "nosso" tomate foi comercializado a R $\$ 0,85$ (valor definido em reunião da qual partici- param representantes do supermercado e da Sakata-Agroflora, acadêmica da área de pós-colheita e o produtor rural), enquanto o quilo do 'Carmem' estava sendo oferecido a R \$ 0,69.

Etapa 6: Avaliação da satisfação do cliente

O "nosso" tomate obteve valor 5 para os itens aparência externa, firmeza, sabor, forma, tamanho, durabilidade, aparência interna, ausência de agrotóxicos, e, adequado para salada; e valor 4 para o item cor. O tomate Carmem, na mesma ocasião, obteve nota 4 para os itens cor, firmeza, sabor, forma, tamanho, durabilidade e aparência interna, e nota 3 para aparência externa, ausência de agrotóxicos, e, adequado para salada. Todos os itens avaliados obtiveram pontuação igual ou superior ao valor estabelecido na Qualidade Planejada, o que indica que as etapas que levaram à oferta do produto obtiveram sucesso. Quanto ao volume 


\begin{tabular}{|c|c|c|c|c|c|c|c|}
\hline \multicolumn{2}{|c|}{ Características da qualidade } & \multicolumn{4}{|c|}{$\begin{array}{l}\text { Análise de } \\
\text { criticidade }\end{array}$} & \multirow[b]{2}{*}{ 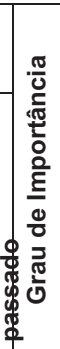 } & \multirow[t]{2}{*}{ Desvio de Especificação } \\
\hline $\begin{array}{l}\text { Item de } \\
\text { controle }\end{array}$ & Especificação & 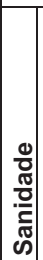 & & $\begin{array}{l}\frac{0}{0} \\
\frac{\pi}{0} \\
\frac{\pi}{0} \\
\frac{0}{\pi} \\
\frac{10}{0}\end{array}$ & 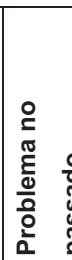 & & \\
\hline $\begin{array}{l}\text { defeitos leves } \\
(\%)\end{array}$ & $<1 \%$ & & 1 & 3 & 9 & 13 & $\begin{array}{l}\text { Comprometimento da aparência do } \\
\text { produto, risco de diminuir durabilidade, } \\
\text { possibilidade de alteração do sabor }\end{array}$ \\
\hline $\begin{array}{l}\text { defeitos graves } \\
\text { (\%) }\end{array}$ & $0 \%$ & & 3 & 9 & 9 & 21 & $\begin{array}{l}\text { Elevado comprometimento da aparência } \\
\text { do produto, redução da durabilidade, } \\
\text { comprometimento do sabor }\end{array}$ \\
\hline $\begin{array}{l}\text { frutos com } \\
\text { sujidades (\%) }\end{array}$ & $0 \%$ & & 1 & 1 & 3 & 5 & $\begin{array}{l}\text { Comprometimento da aparência do } \\
\text { produto, risco de crescimento } \\
\text { microbiano com redução da } \\
\text { durabilidade, possibilidade de } \\
\text { apresentar odores estranhos }\end{array}$ \\
\hline padrão de cor & $\begin{array}{l}\text { "salada" e } \\
\text { "colorido" }\end{array}$ & & 9 & 9 & 9 & 27 & $\begin{array}{l}\text { Comprometimento da aparência do } \\
\text { produto, redução da durabilidade, } \\
\text { possibilidade de sabor não ser } \\
\text { satisfatório }\end{array}$ \\
\hline frutos firmes (\%) & $100 \%$ & & 9 & 9 & 9 & 27 & $\begin{array}{l}\text { Comprometimento da durabilidade, do } \\
\text { sabor e da aparência interna do produto. } \\
\text { Possibilidade de textura anormal, } \\
\text { dificuldade de preparo (corte) do } \\
\text { produto }\end{array}$ \\
\hline Calibre & $\begin{array}{l}=6,0 \quad 0,5 \\
\mathrm{~cm}\end{array}$ & & 1 & 1 & 3 & 5 & $\begin{array}{l}\text { Dificuldade na acomodação na } \\
\text { embalagem, comprometimento da } \\
\text { aparência }\end{array}$ \\
\hline "shelf life" & $\begin{array}{l}>7 \text { dias (no } \\
\text { domicílio do } \\
\text { consumidor) }\end{array}$ & & 9 & 9 & 9 & 27 & $\begin{array}{l}\text { Comprometimento do sabor, da } \\
\text { aparência, das características de textura } \\
\text { e odor do produto }\end{array}$ \\
\hline $\begin{array}{l}\text { frutos brocados } \\
\text { (\%) }\end{array}$ & $0 \%$ & & 9 & 9 & 3 & 21 & $\begin{array}{l}\text { Comprometimento da aparência externa } \\
\text { e interna, do sabor, forte impacto } \\
\text { negativo no consumidor }\end{array}$ \\
\hline $\begin{array}{l}\text { teor de resíduos } \\
\text { de agrotóxicos }\end{array}$ & $\begin{array}{l}\text { Ausência de } \\
\text { qualquer } \\
\text { resíduo }\end{array}$ & 9 & 9 & & 9 & 27 & $\begin{array}{l}\text { Risco à saúde do consumidor, } \\
\text { possibilidade de alteração no odor e } \\
\text { sabor do produto, indução à } \\
\text { desconfiança do consumidor }\end{array}$ \\
\hline
\end{tabular}

Análise de criticidade: 1. Pouca importância; 3. Média importância; 9. Muito importante. Grau de importância = soma dos valores de criticidade do item de controle.

Figura 3. Tabela de Garantia de Qualidade para lotes de Tomate Comercializados pela loja Carrefour D.Pedro. Campinas, SP, 2000. vendido e às perdas, observou-se que todo o lote foi comercializado em 3 dias e não se perdeu um único fruto exposto, ou seja, obteve-se Perdas $=0 \%$. O que indica a aceitação efetiva do produto, e o alcance da meta de vender o lote em 3 dias, possibilitando que o consumidor submeta o tomate ao frio até o $4^{\circ}$ dia após a colheita. Da mesma forma, a eliminação das perdas aponta o acerto no desenvolvimento do produto, principalmente ao se observar o índice de perdas do tomate 'Carmem' no período, que foi de $7 \%$.

Dos 80 julgamentos realizados na Análise Sensorial, 62 apontaram preferência pelo "nosso" tomate, 14 pelo Carmem e 4 indicaram indiferença. Considerando que, para 80 julgamentos, são necessários ao menos 56 respostas favoráveis a uma amostra para se constatar preferência entre duas amostras ao nível de $0,1 \%$ de probabilidade (Moraes, 1988), verifica-se que o "nosso" tomate foi o preferido. Esses resultados confirmam o sucesso alcançado com o trabalho, indicando que a escolha da cultivar foi acertada, assim como os procedimentos foram adequados.

Etapa 7: Estabelecimento da padronização final

Os procedimentos foram revistos, e atenção foi dada à questão da comprovação da sanidade do produto, assim, propôs-se diminuir a freqüência das análises de resíduos a serem realizadas.

Etapa 8: Reflexão sobre o processo de desenvolvimento

O uso do método QFD no desenvolvimento do tomate de mesa para comercialização na loja Carrefour D.Pedro apresentou peculiaridades relacionadas à natureza do produto, pois o fato do tomate não sofrer um processamento propriamente dito, que o alterasse, inserindo ou atenuando alguma característica, imprimiu ao trabalho uma particularidade nova, diferenciando-o totalmente dos relatos encontrados na literatura. Apenas no curso do trabalho é que definiu-se que trata-se de um serviço, que trabalha com um produto, que busca selecioná-lo por características de qualidade, mantendo essas características ao longo de todo processo. Para alcançar os resultados do lote piloto, os insumos humanos represen- 
taram mais de $50 \%$ dos insumos envolvidos, evidenciando que, na área de hortaliças "in natura", o trabalho humano é imprescindível para atingir a qualidade. Um dos aspectos que mais chamou a atenção foi a capacidade do método em fazer interagir as áreas interfuncionais, pois as etapas exigem a participação de outros setores envolvidos. Pode-se entender o QFD como um método de "marketing", pois trabalha com os clientes e fornece estratégias de venda do produto. Foi bastante efetivo na questão das perdas, uma vez que evitou que produto de má qualidade chegasse à banca.

Este trabalho não cobriu todos os possíveis desdobramentos, sendo esperado que detalhamentos envolvendo a área gerencial da loja, bem como a área agrícola, complementariam os procedimentos e consolidariam os resultados.

\section{AGRADECIMENTOS}

Os autores agradecem à CAPES, pela bolsa PICDT concedida ao primeiro autor, ao Carrefour, à Sakata/ Agroflora, ao produtor Sr. José Osvaldo Kitagawa, à FEB e à FEAGRIUNICAMP.

\section{LITERATURA CITADA}

ASSOCIAÇÃO BRASILEIRA DE SUPERMERCADOS - ABRAS. Ranking 2001. Disponível em: $<$ http://www.abras.com.br>. Acesso em 15 maio 2001. BELIK, W.; CHAIM, N.A. Formas híbridas de coordenação na distribuição de frutas, legumes e verduras no Brasil. Cadernos de Debate, Campinas, v. VII, p. 1-9, 1999.

CAMARGO FILHO, W.P. Perspectivas dos mercados de tomate para indústria e mesa. Informações Econômicas, São Paulo, v. 31, n. 5, p. 51-54, maio 2001.

CASTRO, L.R. Influência de aspectos de classificação, embalagem e refrigeração na conservação pós-colheita de tomate "Santa Clara" $e$ "Carmem". Campinas: UNICAMP, 2000. 159 p. (Tese mestrado)

CHENG, L.C.; SCAPIN, C.A.; OLIVEIRA, C.A.; KRAFETUSKI, E.; DRUMOND, F.B.; BOAN, F.S.; PRATES, L.R.; VILELA, R.M. QFD: Planejamento da qualidade. Belo Horizonte: Fundação Christiano Ottoni, 1995. 261 p.

COCHRAN, W.G. Sampling techniques. New York: John Wiley \& Sons, 1977. 428 p.

COSTA, F.G.; CAIXETA FILHO, J.V. Análise das perdas na comercialização de tomate: um estudo de caso. Informações Econômicas, São Paulo, v. 26, n. 12, p. 9-24, 1996.

DELLA VECCHIA, P.T.; KOCH, P.S. Tomates longa vida: o que são, como foram desenvolvidos? Horticultura Brasileira, Brasília, v. 18, n. 1, p. 3-4, 2000.

DURIGAN, J.F.; CHURATA-MASCA, M.G.C. Aspectos pós-colheita de tomate. In: Encontro Nacional de Produção e Abastecimento de Tomate. $2^{\circ}, 8$ a 11/10/91, promoção FCAV, SOB, ANDEF, FUNEP, p. 245-256, 1991.
FAO. Production Year Book, 50. Washington: USDA - Economic Research Service, 1998.

FONSECA, M.C.P; SILVA, M.A.A.P.; SALAY, E. Atitudes dos consumidores com relação à compra de hortifrutícolas em hipermercados e sacolões na cidade de Campinas - SP. Cadernos de Debate, Campinas, v. VI, p. 71-94, 1998.

GORENSTEIN, O. Uma abordagem sobre residuos de agrotóxicos em alimentos frescos. IEA, São Paulo. Disponível em:< http:// www.iea.sp.gov.br/residuos.htm>. Acesso em: 09 maio 2000.

HORTFRUTI: natureza a favor dos negócios. Superhiper, São Paulo, v. 26, n. 304, p. 20-23, 2000.

LEE, G.H.; BUNN, J.M.; HAN, Y.J.; CHRISTENBURY, G.D. Ripening characteristics of light irradiated tomatoes. Journal of Food Science, v. 62, n. 1, p. 138-140, 1997.

MACHADO FILHO, C.A.P.; SPERS, E.E.; CHADDAD, F.R.; NEVES, M.F. Agribusiness Europeu. $1^{a}$ ed., São Paulo: Pioneira, 1996, 132 p. MINISTÉRIO DA AGRICULTURA, DO ABASTECIMENTO E DA REFORMA AGRÁRIA. Relatório preliminar da Comissão Técnica para Redução das Perdas na Agropecuária. Brasília: MAARA, $1993.78 \mathrm{p}$.

MORAES, M.A.C. Métodos para avaliação sensorial dos alimentos. Campinas: Editora da UNICAMP. $6^{a}$ ed., 1988 (Série Manuais). 93 p. OKEZIE, B.O. World food security: the role of postharvest technology. Food Technology, v. 52, n. 1, p. 64-69, 1998

VILELA, N.J.; MACEDO, M.C. Fluxo de poder no agronegócio: o caso das hortaliças. Horticultura Brasileira, Brasília, v. 18, n. 2, p. 88-94, 2000. 